\title{
A Abordagem CTS e a Educação Matemática Crítica como Estratégia de Ensino-Aprendizagem na Formação de Professores de Matemática
}

\section{The CTS Approach and Critical Mathematics Education as a Teaching-Learning Strategy in Teacher Training in Mathematics}

\author{
Maria de Fátima Costa Sbrana ${ }^{\text {a }}$; Evonir Albrecht ${ }^{\mathrm{a}}$; Marcia Aguiar ${ }^{\mathrm{a}}$
}

a Centro de Matemática Computação e Cognição, Universidade Federal do ABC, Santo André, Brasil fatima.sbrana@ufabc.edu.br, evonir.albrecht@ufabc.edu.br,marcia.aguiar@ufabc.edu.br

Palavras-chave: Abordagem CTS Educação matemática crítica. Ensino de matemática.
Keywords:

STS approach. Critical mathematics education. Mathematics teaching.
Resumo: Este artigo está embasado em uma pesquisa de mestrado e tem como objetivo discutir aspectos relevantes de um curso de formação continuada, para professores que ensinam Matemática, com base nas abordagens CTS (Ciência, Tecnologia e Sociedade) e EMC (Educação Matemática Crítica). A pesquisa, de natureza qualitativa, ocorreu em dois momentos. Primeiramente, realizamos uma análise das questões de Matemática contidas no ENEM (Exame Nacional de Ensino Médio) (2012-2016), para investigar se tais questões possuíam em seu contexto, questionamentos relacionados à abordagem CTS. Em um segundo momento, considerando o tripé: Ensino, Pesquisa e Extensão, desenvolvemos um curso de extensão, com base nas abordagens CTS e EMC, com o objetivo de identificar como os professores compreendem as abordagens CTS e EMC e de que maneira eles incorporam a temática em sua prática, além de construir com os professores, estratégias contextualizadas para o ensino da Matemática. As questões analisadas foram utilizadas como instrumento de ensino-aprendizagem para discutir possibilidades de incluir as abordagens CTS e EMC no ensino de Matemática. Observamos que os professores não conheciam as abordagens CTS e EMC, tampouco contemplavam a temática em sua prática. Desta forma, ressaltamos a importância dos cursos de formação continuada, pois apresenta ao professor novas estratégias didático-pedagógicas, bem como, possibilita discussões importantes sobre a sua prática.
Abstract: This article is based in a master's research and to discuss relevant aspects of a continuing education course for teachers who teach mathematics, based on the CTS approach (Science, technology and society) and Critical Mathematics Education approaches. The research qualitative, occurred in two moments. First, we performed an analysis of mathematics issues contained in the ENEM (National High School Exam) (2012-2016), to investigate if such questions had in their context, questions related to the CTS approach. In a second moment, considering the tripod: Teaching, Research and Extension, we developed a continuing education course, based on the CTS and EMC approaches, to identify how teachers understand the CTS and EMC approaches and how they incorporate the theme in their practice, and build with teachers, contextualized strategies for teaching mathematics. The 
analyzed questions were used as a teaching-learning tool to discuss possibilities to include the CTS and EMC approaches in mathematics teaching. We observed that teachers did not know the CTS and EMC approaches; either did they consider the subject matter in their practice. In this way, we emphasize the importance of continuing education courses, as it presents the teacher with new didacticpedagogical strategies, as well as, it allows important discussions about their practice.

\section{Introdução}

Este relato de pesquisa pretende discutir os aspectos relevantes de um Curso de Extensão para professores que ensinam Matemática, tendo como base a contribuição da abordagem CTS e da Educação Matemática Crítica. Para tanto, abordaremos autores que articulam conceitos e concepções a respeito da Ciência, da abordagem CTS, do ensino e ainda, discutiremos elementos que indicam a aproximação das abordagens CTS e EMC.

\section{A Ciência e suas concepções}

Segundo Dal-Farra (2010) são muitos os questionamentos sobre a neutralidade da Ciência e a suposta superioridade da Ciência em relação às demais formas de conhecimento. A convicção de que a Ciência é a única forma de gerar conhecimento, desprezando-se a Cultura como espaço de conhecimento, teve como consequência o ensino de uma Ciência supostamente neutra (DAL-FARRA, 2010).

As principais concepções de Ciência na história, segundo Chauí (2000), são a concepção racionalista, a empirista e a construtivista. A concepção racionalista é hipotéticodedutiva, pois define o objeto e suas leis e a partir disso deduz propriedades, efeitos, previsões e defende que há um critério único, atemporal e universal para se avaliar uma teoria, tendo como referência a objetividade da Matemática. Na concepção racionalista tudo o que a Ciência produz é visto como inerentemente bom (CHALMERS, 1993; CHAUÍ, 2000).

A concepção empirista é hipotético-indutiva, pois apresenta suposições sobre o objeto, efetua observações e experimentos até definir os fatos, as leis, as propriedades, os efeitos posteriores e as previsões. Não concorda com um padrão de racionalidade universal e não histórico. Na concepção empirista, o objetivo do que se busca como conhecimento depende do que é valorizado pelo indivíduo ou comunidade (CHALMERS, 1993; CHAUÍ, 2000). No entanto, as duas concepções racionalista e empirista consideram que "os objetos são préconstituídos, a observação é neutra e o conhecimento corresponde à realidade" (SANTOS, 2010, p.72).

$\mathrm{Na}$ concepção construtivista, o método é considerado pois permite estabelecer definições e deduções sobre o objeto, como também, a experimentação é considerada, pois orienta e altera definições e demonstrações. Contudo, na concepção construtivista, diferentemente das outras concepções, a Ciência não apresenta uma verdade absoluta, mas é 
considerada uma construção de modelos que "explicam" a realidade, apresentando uma verdade aproximada, que pode ser corrigida, modificada, alterada (CHAUÍ, 2000).

Nesta perspectiva, Bizzo (2012) ressalta que "a maneira como se concebe a Ciência tem repercussão direta sobre a maneira como ela é ensinada" (BIZZO, 2012, p. 151). Fiorentini (1995) contribui ao afirmar que a forma como compreendemos a Matemática implica no modo como compreendemos e praticamos o ensino da Matemática e vice-versa. Se a Ciência é compreendida como a única forma de produzir conhecimento, acreditando-se que o que ela produz é inquestionável (racionalismo), ou se a esta compreensão for acrescentada a necessidade de uma comunidade científica que deve concordar com as teorias estudadas (empirismo), o professor defenderá o ensino de Ciências com argumentos que apontam para o entendimento de uma Ciência neutra.

Desta forma, a convicção de que os problemas da Sociedade serão solucionados com o desenvolvimento científico-tecnológico, a ideia de progresso inevitável, ou seja, a neutralidade e suposta superioridade da Ciência, podem influenciar o ensino, afirma Auler (2011). Aprender Ciência por meio de sua pura e simples memorização é resultado da crença de que não há vantagem real em entendê-la, até mesmo os conceitos simples (BIZZO, 2012).

Dal-Farra (2010) ressalta que os educadores repensaram as concepções existentes sobre a Ciência, no século XX, a partir da década de 1990, pelos seguintes motivos

\begin{abstract}
a) a afirmação do construtivismo como tendência na educação científica, considerando que a aprendizagem ocorre a partir dos conhecimentos prévios; b) o foco de as pesquisas sobre currículo estarem voltadas para a compreensão dos processos históricos de sua construção, considerando o currículo como fruto de conflitos entre grupos sociais que pretendem valorizar determinados conhecimentos em detrimento de outros; e, por último, c) o fato de diversos grupos sociais e culturais apresentarem um olhar mais cético em relação à ciência ocidental moderna, em decorrência das suas consequências sobre o ambiente e a sociedade (DALFARRA, 2010, p. 510).
\end{abstract}

Dessa maneira, o construtivismo, as pesquisas em relação ao currículo, como também, a desaprovação em relação à Ciência Moderna contribuíra para a reflexão em torno das concepções presentes na Educação em Ciências. Discutiremos nesse artigo o item c.

\title{
A abordagem CTS e a Educação Matemática Crítica
}

Foi nos finais dos anos 1960 e início dos anos 1970, na Europa e nos EUA, a partir das críticas de grupos sociais sobre às consequências do desenvolvimento da Ciência e da Tecnologia na Sociedade e das discussões sobre a natureza do conhecimento científico, que surgiu o movimento CTS (BAZZO et al., 2003).

Dessa forma, o movimento CTS contesta o determinismo tecnológico, ou seja, a concepção que entende que o desenvolvimento científico resulta em desenvolvimento social (BAZZO et al., 2003). Morin (2005) reflete sobre o papel da Ciência moderna na Sociedade e expressa a precisão da formação de cidadãos que compreendam tal papel 
A Ciência é um processo sério demais para ser deixado só nas mãos dos cientistas. Eu completaria dizendo que a Ciência se tornou muito perigosa para ser deixada nas mãos dos estadistas e dos Estados. Dizendo de outra forma, a Ciência passou a ser um problema cívico, um problema dos cidadãos. Precisamos ir ao encontro dos cidadãos (MORIN, 2005, p .133).

Para tanto, o grande desafio da Educação passa a ser a alfabetização científica. Segundo Guazzelli et al. (2009) a alfabetização científica crítica é um processo educacional, que deve proporcionar ao estudante, compreender a natureza da Ciência e da Tecnologia, o papel da Ciência e da Tecnologia na Sociedade, além do seu papel como cidadão, possibilitando a sua participação nas decisões que envolvem a Ciência e a Tecnologia no ambiente social.

Segundo Santos (2010), entre os anos 1960 e 1970, o ensino tradicional promoveu um ensino de Ciências que, com o objetivo de preparar os estudantes para pensarem como cientistas, buscou treiná-los para lidar com instrumentos de laboratório de investigação e produzir Ciência de uma forma que simulasse o método científico. Esse ensino está embasado na Ciência pura, identificando a Ciência com a "capacidade de produção de conhecimento, independentemente de suas aplicações" (SANTOS, 2010, p.73). Um ensino que reforça o mito de que tudo que a Ciência faz é bom, promove o conhecer por conhecer, valoriza a Ciência moderna e subestima a importância de utilizar conceitos científicos na vida real (SANTOS, 2010).

A abordagem CTS propõe o conhecimento científico tecnológico a partir do contexto social, favorecendo a formação crítica do estudante e, por consequência, interferindo na Cultura da Sociedade. Segundo Guazzelli et. al (2009), existe um consenso entre diversos autores no que diz respeito a estreita relação ente a Cultura, a Educação e o movimento CTS.

Bazzo et. al (2003) definem os estudos CTS como "campo de trabalho de caráter crítico e interdisciplinar, onde se estuda a dimensão social da Ciência e da Tecnologia (BAZZO et al., 2003, p.159). Desta forma, destacamos o caráter crítico e interdisciplinar dos estudos CTS, no qual "não confina o ensino das Ciências ao estatuto acadêmico da disciplina, aposta na Ciência para o cidadão" (SANTOS, 2010, p. 74).

No entanto, Silva e Albrecht (2010) ressaltam os desafios à ação docente na linha de estudos CTS. Além de uma formação inicial adequada, que proporcione estudos sobre os aspectos sociais, políticos e culturais relacionados à educação científica, citam a necessidade de uma formação interdisciplinar.

Segundo Bazzo e Cury (2001), são poucos os cursos de licenciatura que oferecem uma formação inicial interdisciplinar e que discutam a relação CTS, principalmente quando se trata do ensino de Matemática, que é bastante tradicional. Os autores sugerem a inclusão dos estudos sociais da Ciência e da Tecnologia nos cursos de formação de Matemática, pois consideram que tais estudos permitirão aos futuros professores 
(...) uma imagem mais realista da natureza social da ciência e da tecnologia e a compreensão desses aspectos os levará, gradativamente, a desenvolver a habilidade de questionar as "certezas absolutas" da matemática, a detectar o uso acrítico dessa ciência e a tomar decisões sobre problemas em cujas soluções estão envolvidos conteúdos matemáticos (BAZZO; CURY, 2001, p. 41).

Neste sentido, encontramos na Educação Matemática Crítica a preocupação com as “certezas absolutas", e principalmente, com o papel da Matemática na Sociedade (SKOVSMOSE, 2000). Ole Skovsmose, apoiado nos ideais da Educação Crítica, intenta uma Educação Matemática Crítica, a partir de 1975, na Dinamarca e posteriormente, observa outros contextos, como na África do Sul, Brasil e Colômbia (SKOVSMOSE, 2012).

Os questionamentos em torno da EMC estão direcionados para os aspectos políticos da Educação Matemática, em especial, acerca de “quem interessa que a Educação Matemática seja organizada dessa maneira" (BORBA, 2011, p. 7).

Para Skovsmose (2011), a alfabetização Matemática refere-se à noção de interpretar um mundo estruturado por elementos matemáticos e intervir nesse ambiente. Para tanto, o autor aponta três tipos de conhecimentos matemáticos importantes para a formação dos cidadãos, o conhecimento matemático, o conhecimento tecnológico e o conhecimento reflexivo. O conhecimento matemático refere-se às habilidades matemáticas como a reprodução de teoremas, provas e algoritmos; o conhecimento tecnológico refere-se às habilidades em aplicar a Matemática e modelos matemáticos e ainda, o conhecimento reflexivo, que se refere à competência de refletir sobre o uso da Matemática e a avaliar.

Neste contexto, consideramos a importância de estudar a natureza da Ciência e as relações da Ciência e da Tecnologia com a Sociedade nos cursos de formação de professores, principalmente, para o desenvolvimento do conhecimento reflexivo na Matemática. Sepini e Maciel (2016) contribuem

\footnotetext{
Para que ocorra essa formação cidadã é necessário que durante sua formação os docentes desenvolvam competências em relação ao desenvolvimento e a implementação de novas estratégias de ensino, pois na atualidade deve-se proporcionar práticas e/ou atividades de ensino que valorizem o pensamento crítico e desenvolvam a capacidade de questionamento aos padrões sociais da atualidade, um dos requisitos culturais atrelados a sua formação acadêmica e com implicações na autonomia (SEPINI; MACIEL, 2016, p. 742).
}

Ao refletirmos sobre as considerações de Sepini e Maciel (2016), que mencionam a relevância da valorização do pensamento crítico e questionamentos aos padrões sociais, percebemos que o ensino tradicional, desconexo da Sociedade, da Cultura, não alcança tais objetivos.

Desta forma, as novas estratégias de ensino são essenciais para direcionar o professor em novas práticas pedagógicas que contribuam para uma formação cidadã. Fiorentini (2005) indica em suas pesquisas e experiências que a investigação da realidade e a reflexão compartilhada sobre a prática contribuem de forma eficiente para a formação do professor. 
Nesta perspectiva, os cursos de formação continuada são um caminho para preencher as lacunas de formação e contribuir com a prática do professor. Neste sentido, propusemos um Curso de Extensão para professores que ensinam Matemática, com base nas abordagens CTS e Educação Matemática Crítica, com a finalidade de criar oportunidades de reflexão sobre a atuação docente, a partir das questões apresentadas no ENEM.

\section{Aproximações entre as abordagens CTS e EMC}

Por meio da teoria apresentada nessa seção, buscaremos compreender se a abordagem CTS e a EMC se aproximam e podem ser consideradas para as reflexões sobre Ciência, Tecnologia, Sociedade, Matemática e suas relações. Para tanto, apresentamos o quadro 1, que relaciona os aspectos de aproximação entre as duas abordagens, conforme Sbrana (2017).

Quadro 1 - Aproximação da Abordagem CTS e EMC

\begin{tabular}{|l|l|}
\hline \multicolumn{1}{|c|}{ ABORDAGEM CTS } & \multicolumn{1}{c|}{ EMC } \\
\hline Alfabetização Científica & Alfabetização Matemática \\
\hline Leitura Crítica do Mundo & Interpretação da realidade \\
\hline Participação Consciente e Ativa & Organizar-se para intervir no Contexto Social e Político \\
\hline Contextualização & Cenários para Investigação \\
\hline Diálogo com Outros Conhecimentos & Diálogo com Outros Conhecimentos \\
\hline
\end{tabular}

Fonte: os autores

O termo Alfabetização Científica é citado por Sasseron e Carvalho (2011), com base na definição de alfabetização de Paulo Freire. Como também, o termo Alfabetização Matemática de Skovsmose (2012).

Sasseron e Carvalho (2011) esclarecem que, para Paulo Freire, a Alfabetização supera o domínio da técnica de ler e escrever, possibilitando a leitura e a transformação do mundo, por meio de uma consciência crítica. Skovsmose (2012) explica que, para Freire a Alfabetização é a capacidade de leitura (interpretar os fenômenos sociopolíticos) e escrita (ser capaz de promover mudanças) no mundo.

Nesta perspectiva, a Alfabetização Científica tem o propósito de situar o indivíduo em um mundo científico e tecnológico e de utilizar as Ciências para compreender esse mundo, participando da Cultura do nosso tempo (FOUREZ, 2003).

Para Skovsmose (2012) a Alfabetização Matemática pode ser interpretada como "a capacidade de se interpretar um mundo estruturado por números e figuras, e à capacidade de se atuar nesse mundo" (SKOVSMOSE, 2012, p. 19).

Desta forma, a Alfabetização Científica e a Alfabetização Matemática se aproximam na perspectiva da formação dos cidadãos, preparando-os para a leitura crítica do mundo onde vivem, possibilitando a sua participação no sentido de promover mudanças em assuntos que 
envolvem a Ciência e a Tecnologia em uma Sociedade matematizada e tecnológica (SBRANA, 2017).

No entanto, a abordagem CTS se refere a uma leitura crítica do mundo que "mobiliza o cidadão" para a participação consciente e ativa (SANTOS, 2010, p. 74) e a EMC se refere à interpretação da realidade, para que tenham condições de organizar-se para intervir no contexto social e político, possibilitando transformações de tendência científica, tecnológica e social (SKOVSMOSE, 2011).

Além disso, a abordagem CTS contempla um ensino de Ciências que valoriza a contextualização a partir da realidade, do contexto histórico, social e cultural e da interdisciplinaridade (SANTOS, 2010). A EMC contempla os Cenários para Investigação, que orienta um ensino de Matemática que considera o contexto social, científico, tecnológico (SKOVSMOSE, 2014) e interdisciplinar. Neste sentido, um elemento de aproximação das abordagens CTS e EMC é a contextualização a partir de uma perspectiva histórica, social e cultural.

Desta forma, as estratégias de ensino utilizadas na formação de professores foram as abordagens CTS e EMC, com o propósito de apresentar um ensino de Matemática orientado para a formação do cidadão que compreende as implicações da Ciência e da Tecnologia na Sociedade.

\section{A metodologia da pesquisa e o curso de extensão}

O objetivo da pesquisa, de caráter qualitativo, foi investigar como as abordagens CTS e EMC podem contribuir com o ensino contextualizado da Matemática. A pesquisa ocorreu em dois momentos. No primeiro momento utilizamos como metodologia a análise de conteúdo de Bardin (2011) e realizamos a análise das questões de Matemática do ENEM, do período de 2012 a 2016, com o intuito de verificar se e quais questões apresentavam em seu contexto a relação entre a Ciência, a Tecnologia e a Sociedade. As questões analisadas do ENEM foram utilizadas como instrumentos de ensino-aprendizagem em um Curso de Extensão para professores que ensinam Matemática.

No segundo momento, considerando o tripé: Ensino, Pesquisa e Extensão, desenvolvemos o Curso de Extensão, com base nas abordagens CTS e EMC, com o objetivo de identificar como os professores compreendem as abordagens CTS e EMC e de que maneira eles incorporam a temática em sua prática, além de construir com os professores, estratégias contextualizadas de ensino da Matemática.

O Curso de Extensão teve como título "Abordagens de Ensino de Matemática e o ENEM" e foi realizado nas dependências da Universidade Federal do ABC, através da PróReitoria de Educação e Cultura (ProEc). 
Os professores que ensinam Matemática na Educação Básica formaram o público alvo do curso. Obtivemos quarenta e duas inscrições, no entanto, doze professores finalizaram o curso. Serão apresentados neste trabalho, os dados utilizados para análise, correspondente aos doze professores. Segue o quadro 2, que demonstra a caracterização dos professores participantes do curso.

Quadro 1 - Caracterização dos Participantes

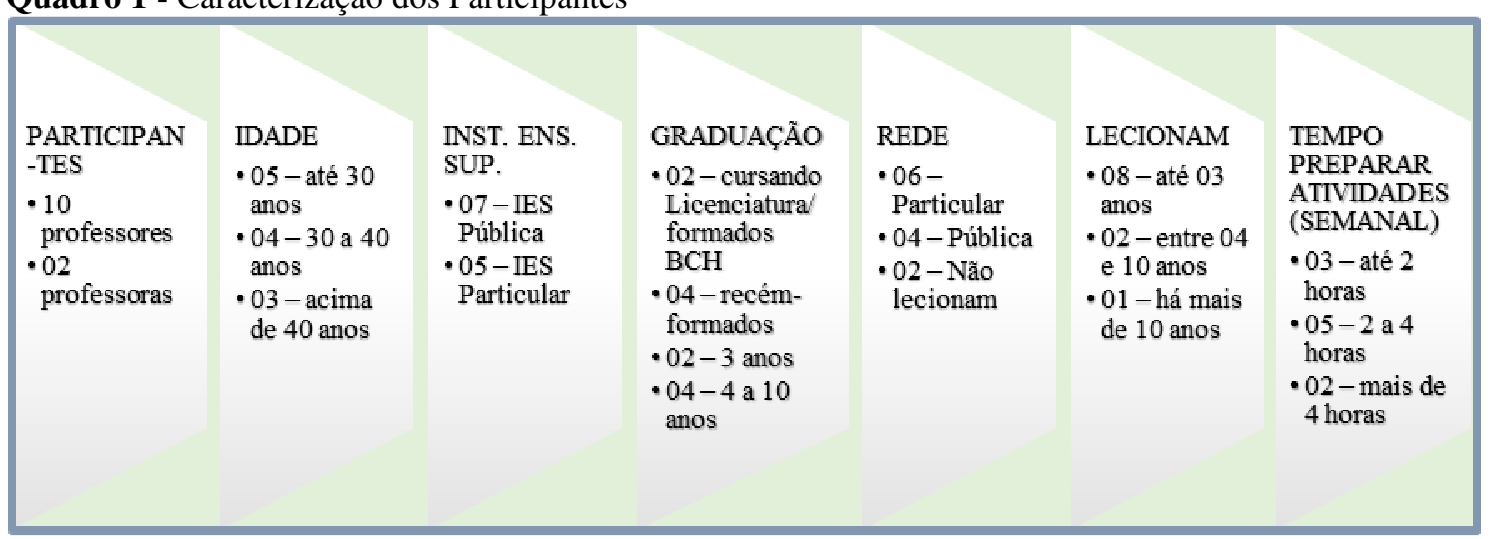

Fonte: os autores

O curso foi realizado em 4 encontros presenciais com 3 horas e meia cada, além de 6 horas de atividades complementares não presenciais, que incluíram leitura de artigos e elaboração de atividades, totalizando 20 horas de curso. Os encontros ocorreram da seguinte forma:

No $1^{\circ}$ encontro, as atividades e temas abordados foram: 1. Aplicação do questionário; 2. Apresentação dos participantes; 3. Apresentação do curso; 4. Percepção pública da C\&T no Brasil; 5. Leitura e discussão do artigo "O Despertar da Radioatividade ao Alvorecer do Século XX, com os objetivos de identificar os conhecimentos prévios e iniciais dos professores participantes; apresentar a percepção dos brasileiros em relação a Ciência e Tecnologia; discutir sobre a visão que os professores participantes possuem em relação à Ciência e a Tecnologia.

No $2^{\circ}$ encontro, as atividades e temas abordados foram: 1. a contextualização na Matemática; 2.a abordagem CTS; 3. a Educação Matemática Crítica; 4. apresentação das questões selecionadas do ENEM e discussão, com os objetivos de apresentar os conceitos da abordagem CTS e discutir a sua aplicação no ensino de Matemática, a importância da contextualização no ensino de Matemática e os pressupostos da EMC.

No $3^{\circ}$ encontro, as atividades e temas abordados foram: 1 . atividade em grupo: análise das Questões do ENEM; 2. os conteúdos que envolvem CTS; 3. atividade em grupo: elaboração de atividade que envolve CTS e EMC, com o objetivo de apresentar possibilidades de inserir a abordagem CTS e a EMC em sala de aula a partir das questões do ENEM . 
No $4^{\text {o }}$ encontro, as atividades e temas abordados foram: 1. apresentação para os grupos da questão escolhida na aula anterior e estratégia para utilizá-la em sala de aula; 2. discussão sobre as estratégias apresentadas; 3 . questionamentos sobre a percepção dos participantes em relação ao curso, com os objetivos de identificar se os conceitos abordados contribuíram para a prática do professor e verificar se e como a abordagem CTS e a EMC podem contribuir para o ensino contextualizado da Matemática.

\section{Descrição e análise de dados}

As análises desta pesquisa estão apoiadas no referencial teórico, que destaca que a abordagem CTS tem como base a articulação entre a Educação científica, a Educação tecnológica e a Educação em questões sociais (CAMPOS, 2010), bem como, nas discussões que apontam que a EMC se preocupa com os aspectos sociopolíticos da Educação Matemática (SKOVSMOSE, 2011). Foram realizadas cinco atividades durante os encontros. As atividades foram importantes como diagnóstico para planejamento das aulas nos encontros. Para demonstrar os recortes das respostas dos professores e preservar a sua identidade, esses foram enumerados de 1 a 12 acrescentando-se o $\mathrm{P}$ para indicar professor.

Atividade 1

A atividade 1 (Quadro 3) foi constituída por um questionário com seis perguntas, respondidas de forma individual, com o intuito de identificar se os professores participantes possuíam algum conhecimento sobre as abordagens CTS e EMC, como também identificar qual era o entendimento dos professores sobre a relação Ciência, Tecnologia e Sociedade. Desta forma, analisamos apenas as questões 3 e 5, sendo que, as demais perguntas foram utilizadas para auxiliar na estrutura do Curso de Extensão.

Quadro 3 - Atividade 1. Questionário

\section{QUESTIONÁRIO}

1. Qual é a sua a compreensão sobre o papel da Ciência e da Tecnologia no ensino de Matemática?

2. O que você entende por contextualização no ensino de Matemática? Dê um exemplo. 3. O que você conhece sobre a abordagem CTS (Ciência, Tecnologia e Sociedade) no ensino?

4. Você considera que o ensino de Matemática pode promover nos alunos reflexões sobre questões que envolvem a Ciência e a Tecnologia na Sociedade? De que forma?

5. Qual é a sua opinião sobre a Educação Matemática Crítica? Dê um exemplo de uma atividade que você utiliza a Matemática Crítica $^{1}$ nas suas aulas?

6. Como você percebe a Educação Matemática e a sua interação com as disciplinas das Ciências, Física, Química e Biologia? De que forma você relaciona os conteúdos trabalhados na Matemática com as outras disciplinas das Ciências?

Fonte: os autores 
O quadro 4 demonstra as respostas obtidas a partir da questão 3 do Questionário (Quadro 3). Por meio desta questão buscamos identificar se os professores possuíam algum conhecimento sobre o propósito da abordagem CTS no ensino.

Quadro 4 - Questão 3. Questionário

\begin{tabular}{|c|l|}
\hline $\begin{array}{c}\mathbf{N}^{\mathbf{0}} \text { de } \\
\text { respostas }\end{array}$ & $\begin{array}{l}\text { 3. O que você conhece sobre a abordagem CTS (Ciência, Tecnologia e Sociedade) } \\
\text { no ensino? }\end{array}$ \\
\hline 04 & Não sabem o significado da abordagem CTS \\
\hline 03 & Não conhecem, mas supõe que tem relação com a Ciência, Tecnologia e cotidiano. \\
\hline 02 & Responderam de forma superficial \\
\hline 01 & Relatou que trata-se da influência da Ciência e da Tecnologia na Sociedade \\
\hline 02 & Não responderam \\
\hline
\end{tabular}

Fonte: os autores

Desta forma, as respostas obtidas a partir da questão 3 demonstraram que nove professores não conheciam a abordagem CTS, dois responderam de forma superficial, não sendo possível identificar que os professores conheciam a abordagem e um professor respondeu sobre a influência da Ciência e da Tecnologia na Sociedade, mas não relacionou com o ensino. Nessa seção, apresentaremos as transcrições na íntegra, para preservar a essência da resposta do professor.

Ao responder sobre o seu conhecimento em relação a abordagem CTS, o professor P7 respondeu que, "seria ter o conhecimento de que a tecnologia ou as ciências aprendidas não estão isoladas no mundo e que elas têm uma influência muito grande na Sociedade e viceversa" (P7).

O professor P7 respondeu a questão demonstrando compreender que a abordagem CTS contempla o conhecimento que reconhece a influência da Ciência e da Tecnologia na Sociedade, como descrevem diversos autores, quando afirmam que a abordagem CTS possui a preocupação com as formas de articular a Ciência e a Tecnologia com a Sociedade (SANTOS, 2005; BAZZO et. al, 2003; AULER, 2007). No entanto, o professor P7, quando questionado, explicou que não conhece a abordagem.

O professor P4 responde sobre a abordagem CTS, "na minha experiência profissional nunca abordei ou vi colegas de trabalho abordando CTS" (P4). Podemos constatar que o professor P4 não conhece a abordagem CTS e não presenciou nenhum colega que utilizasse a abordagem CTS no ensino.

O quadro 5 demonstra as respostas obtidas a partir da questão 5 do Questionário ((Quadro 3)), que investiga a opinião dos participantes, sobre a EMC, solicitando um exemplo de uma atividade que envolve esta abordagem. 
Quadro 5 - Questão 5. Questionário

\begin{tabular}{|c|l|}
\hline $\begin{array}{c}\mathbf{N}^{\mathbf{0}} \text { de } \\
\text { respostas }\end{array}$ & $\begin{array}{l}\text { 5. Qual é a sua opinião sobre a Educação Matemática Crítica? Dê um exemplo de } \\
\text { uma atividade que você utiliza a Matemática Crítica nas suas aulas? }\end{array}$ \\
\hline 05 & Não responderam \\
\hline 03 & Relataram que a abordagem é importante, exemplificaram, mas não explicaram. \\
\hline 02 & Não conhecem, mas supõe que deva ser a capacidade de análise dos dados matemáticos \\
\hline 02 & Relataram não conhecer a abordagem \\
\hline
\end{tabular}

Fonte: os autores

Dentre os professores, doze não demonstraram conhecer a abordagem EMC, apesar de três exemplificarem com situações que envolvem a abordagem, porém, quando questionados, não souberam explicar do que se trata a abordagem no ensino. Apresentamos alguns recortes que demonstram as respostas dos participantes.

Quando leio a palavra "crítica", me vem a cabeça a análise de dados ou a compreensão de uma resposta. Nesse raciocínio, uso isto a todo momento: ao terminar a resolução de um problema, por exemplo, pergunto aos alunos "O que significa esse valor final? O que você entende?" Pergunto pois tento mostrar ao aluno que não basta calcular, temos que refletir sobre o que calculamos (P2).

O professor P2 demonstrou que considera importante a reflexão sobre o significado do que calculamos na Matemática, concordando com as indagações de Skovsmose que ressalta a importância do conhecimento reflexivo na Matemática (SKOVSMOSE, 2014).

O professor P10, em relação a EMC, relata "não posso dar minha opinião pois não conheço o termo crítico ainda mais "educação Matemática crítica". Conheço "Educação Matemática", mais esse termo crítico é novo para mim" (P10). O professor P10 descreve que o termo crítico é desconhecido, principalmente quando relacionado à Educação Matemática.

Atividade 2

Para a atividade 2 (Quadro 6) propomos a leitura do texto "O Despertar da Radioatividade ao Alvorecer do Século XX” (LIMA et al., 2011) com o objetivo de provocar uma discussão para a reflexão sobre o emprego da Ciência e da Tecnologia e os perigos associados a esse emprego.

Quadro 6 - Atividade 2

Leia o texto e socialize as ideias principais com o seu grupo: A divulgação do "radio" apresentada no artigo teve uma preocupação em apresentar os fatos científicos da época? A escola pode ser um divulgador da Ciência? De que modo?

Fonte: os autores

No texto são discutidos diversos benefícios do elemento químico rádio, divulgados por meio de propagandas da época, no entanto, os estudos científicos a respeito desse elemento não haviam sido concluídos. 
As discussões pertinentes a esta atividade foram realizadas em dupla, visto que, sete dos professores compreenderam que não houve uma preocupação em divulgar os dados científicos da época, e cinco entenderam que houve uma preocupação em anunciar os dados científicos. Porém, os doze professores relataram acreditar que a escola deve ser divulgadora da Ciência, discutindo exemplos de como seria possível essa divulgação por meio da escola.

Atividade 3

A atividade 3 (Quadro 7) foi composta por seis questões de Matemática do ENEM (2012-2016), escolhidas pela pesquisadora e tinha como objetivo promover uma discussão sobre os conteúdos, as dificuldades dos estudantes em resolver as questões e se as questões contemplavam ou poderiam contemplar as abordagens CTS e EMC. A atividade foi realizada em grupos com 3 ou 4 participantes, sendo que, os professores deveriam resolver as questões como se fossem os seus alunos.

Nessa atividade, os grupos apresentaram as suas respectivas soluções para todos os participantes, momento em que houve uma discussão sobre outras formas de resolução das questões, no entanto, os grupos fizeram poucas menções sobre a possibilidade de trabalhar com as abordagens CTS e EMC. Apresentaremos nesse trabalho, as resoluções dos grupos 1 e 2.

O grupo 1 respondeu à pergunta 1 da atividade 3 (Quadro 7), demonstrando a resolução de cada uma das questões. No entanto, o grupo respondeu de forma genérica a questão 2, como podemos verificar na transcrição, "sim, existe a possibilidade, por exemplo a questão 146 você consegue trabalhar relacionando a exemplos na produção de materiais, com custo e benefícios. A questão 153 você consegue trabalhar a quantidade em diversos contextos" (Grupo 1).

Quando o grupo 1 cita que existe a possibilidade de trabalhar com CTS e EMC, principalmente com relação a questão 146, que possui um contexto puramente matemático, menciona a produção de materiais. Desta forma, o grupo demonstra não compreender ainda que as questões devem ter um contexto que envolve um problema social.

Os integrantes do grupo 2 não resolveram as questões, apenas citaram, em cada questão, quais seriam os métodos que eles acreditavam que os seus alunos utilizariam para responder as questões. Com referência a pergunta 2, sobre a possibilidade de trabalhar com a abordagem CTS e/ou com a EMC, o grupo respondeu que a maior parte das questões poderia ser relacionada com a realidade (Figuras 1, 2, 3, 4, 5 e 6). 
Quadro 7 - Atividade 3. Questões do ENEM

Para cada uma das questões abaixo, responda:

1. Como você acredita que os estudantes resolveriam essa questão?

2. Existe a possibilidade de trabalhar com a abordagem CTS e/ou a Educação Matemática Crítica nessa questão?

\section{Questão 180 - ENEM 2013}

A Secretaria de Saúde de um município avalia um programa que disponibiliza, para cada aluno de uma escola municipal, uma bicicleta, que deve ser usada no trajeto de ida e volta, entre sua casa e a escola. Na fase de implantação do programa, o aluno que morava mais distante da escola realizou sempre o mesmo trajeto, representado na Figura, na escala 1: 25 000, por um período de cinco dias. Quantos quilômetros esse aluno percorreu na fase de implantação do programa?

\section{Questão 162 - ENEM 2013}

Em setembro de 1987, Goiânia foi palco do maior acidente radioativo ocorrido no Brasil, quando uma amostra de césio-137, removida de um aparelho de radioterapia abandonado, foi manipulada inadvertidamente por parte da população. A meia-vida de um material radioativo é o tempo necessário para que a massa desse material se reduza à metade. A meia-vida do césio-137 é 30 anos e a quantidade restante de massa de um material radioativo, após t anos, é calculada pela expressão $\mathrm{M}(\mathrm{t})=\mathrm{A} \cdot(2,7) \mathrm{kt}$, onde $\mathrm{A}$ é a massa inicial e k é uma constante negativa. Considere 0,3 como aproximação para $\log 102$. Qual o tempo necessário, em anos, para que uma quantidade de massa do césio-137 se reduza a $10 \%$ da quantidade inicial?

\section{Questão 165 - ENEM 2014}

Durante a Segunda Guerra Mundial, para decifrarem as mensagens secretas, foi utilizada a técnica de decomposição em fatores primos. Um número $\mathrm{N}$ é dado pela expressão $2 \mathrm{x}$. $5 \mathrm{y}$. $7 \mathrm{z}$, na qual x, y e z são números inteiros não negativos. Sabe-se que N é múltiplo de 10 e não é múltiplo de 7 . O número de divisores de $\mathrm{N}$, diferentes de $\mathrm{N}$, é

\section{QUESTÃO 180 - ENEM 2015}

Em uma central de atendimento, cem pessoas receberam senhas numeradas de 1 até 100 . Uma das senhas é sorteada ao acaso. Qual é a probabilidade de a senha sorteada ser um número de 1 a 20 ?

Questão 153 - ENEM 2016

O Brasil é o quarto produtor mundial de alimentos e é também um dos campeões mundiais de desperdício. São produzidas por ano, aproximadamente, 150 milhões de toneladas de alimentos e, desse total, 23 são produtos de plantio. Em relação ao que se planta, 64\% são perdidos ao longo da cadeia produtiva (20\% perdidos na colheita, $8 \%$ no transporte e armazenamento, $15 \%$ na indústria de processamento, $1 \%$ no varejo e o restante no processamento culinário e hábitos alimentares). O desperdício durante o processamento culinário e hábitos alimentares, em milhão de tonelada, é igual a:

\section{Questão 146 - ENEM 2016}

Uma indústria de perfumes embala seus produtos, atualmente, em frascos esféricos de raio R, com volume

dado por $\frac{4}{3} \cdot \pi \cdot(R)^{3}$. Observou-se que haverá redução de custos se forem utilizados frascos

cilíndricos com raio da base $\frac{\pi}{3}$, cujo volume será dado por $\pi \cdot\left(\frac{\pi}{3}\right)^{2} \cdot h$, sendo $\mathrm{h}$ a altura da nova

embalagem. Para que seja mantida a mesma capacidade do frasco esférico, a altura do frasco cilíndrico (em termos de R) deverá ser igual a:

\section{Fonte: INEP}




\section{Questão 180 - ENEM 2013}

A Secretaria de Saúde de um município avalia um programa que disponibiliza, para cada aluno de uma escola municipal, uma bicicleta, que deve ser usada no trajeto de ida e volta, entre sua casa e a escola. Na fase de implantação do programa, o aluno que morava mais distante da escola realizou sempre o mesmo trajeto, representado na figura, na escala $1: 25000$, por um período de cinco dias.

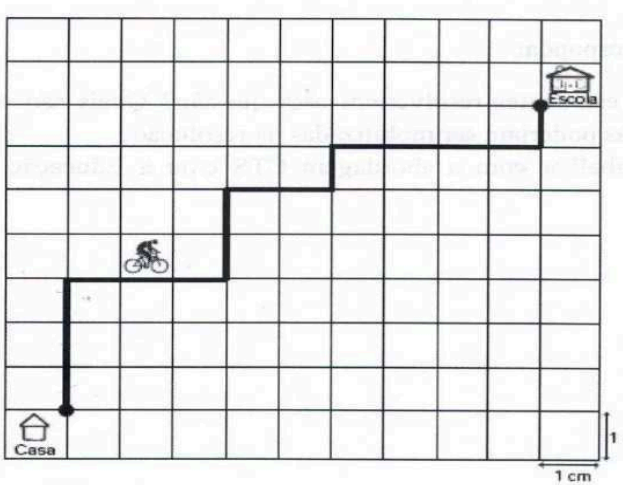

$$
\text { 1) Contanier o no de quadrados; Convertaria }
$$
para a medider real; Multiplicenia for 2 (idu e volta); Faria una regra de 3: 1 dicio $\times \mathrm{Km}$ 5 dies $y \mathrm{~km}$

2) Sim, nois é un excemplo palpaVel e a aluno pode assorion à

Quantos quilômetros esse aluno percorreu na fase de implantação do programa?

A 4

B 8

C 16

E 40

Figura 1 - Atividade 3. Questão 180-ENEM 2013. Grupo 2

Fonte: material de pesquisa

Os professores (Grupo2) acreditam que as questões 180-ENEM 2013 (Figura 1) e 180ENEM 2015 (Figura 2) possibilitam ao estudante associar o contexto à sua realidade e por isso, são questões possíveis de trabalhar com a abordagem CTS e a EMC. A questão 180ENEM 2013 (Figura 1) poderia ser problematizada, caso o professor "aproveitasse" a questão para discutir sobre o problema do trânsito nas grandes cidades, sobre a produção desenfreada de veículos, sobre o problema do combustível, sobre a poluição.

\section{QUESTÃO 180 - ENEM 2015}

Em uma central de atendimento, cem pessoas receberam senhas numeradas de 1 até 100 . Uma das senhas é sorteada ao acaso. Qual é a probabilidade de a senha sorteada ser um número de 1 a 20 ?

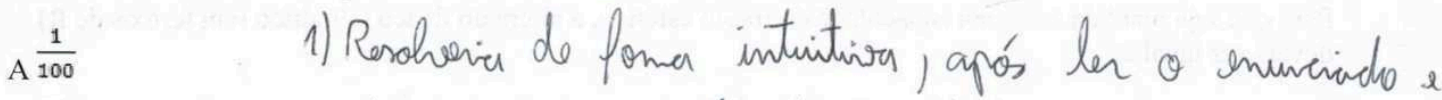

$$
\begin{aligned}
& \text { B } \frac{19}{100} \quad \text { interpretí- lo corretamente. }
\end{aligned}
$$

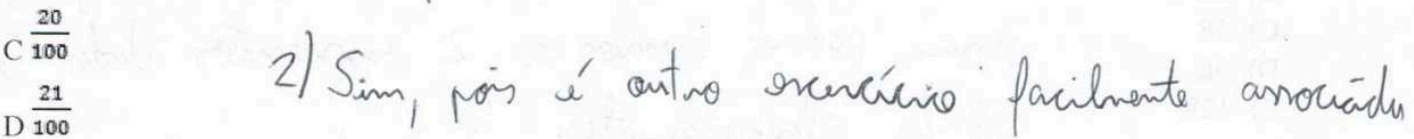

$$
\begin{aligned}
& \text { E } \frac{\text { so }}{100} \quad \text { à nealidede. }
\end{aligned}
$$

Figura 2 - Atividade 3. Questão 180-ENEM 2015. Grupo 2

Fonte: material de pesquisa

No caso da Questão 180-ENEM 2015 (Figura 2) trata-se de uma questão que envolve o cotidiano, mas dificilmente envolveria um problema social. É uma questão que envolve apenas uma aplicação Matemática e que envolve um contexto desconexo com a realidade. 


\section{Questão 146 - ENEM 2016}

Uma indústria de perfumes embala seus produtos, atualmente, em frascos esféricos de raio $\mathrm{R}$, com volume dado por $\frac{4}{3} \cdot \pi \cdot(R)^{3}$

Observou-se que haverá redução de custos se forem utilizados frascos cilíndricos com raio da base $\frac{R}{3}$, cujo volume será dado por $\pi \cdot\left(\frac{R}{3}\right)^{2} \cdot h$, sendo $\mathrm{h}$ a altura da nova embalagem.

Para que seja mantida a mesma capacidade do frasco esférico, a altura do frasco cilíndrico (em termos de R) deverá ser igual a:
A) $2 R$
B) $4 \mathrm{R}$
C) $6 \mathrm{R}$
D) $9 R$
E) $12 R$
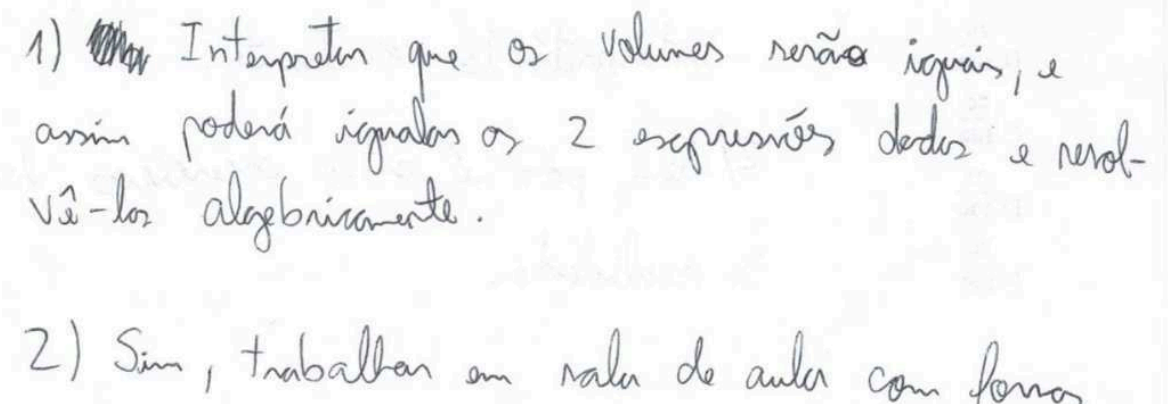

Figura 3 - Atividade 3. Questão 146-ENEM 2016. Grupo 2

Fonte: Material de pesquisa

Com referência à questão 146-ENEM 2016 (Figura 3) que possui em seu contexto uma aplicação puramente Matemática, para os professores (Grupo 2), "são formas e modelos palpáveis", por isso, possíveis de trabalhar com as abordagens.

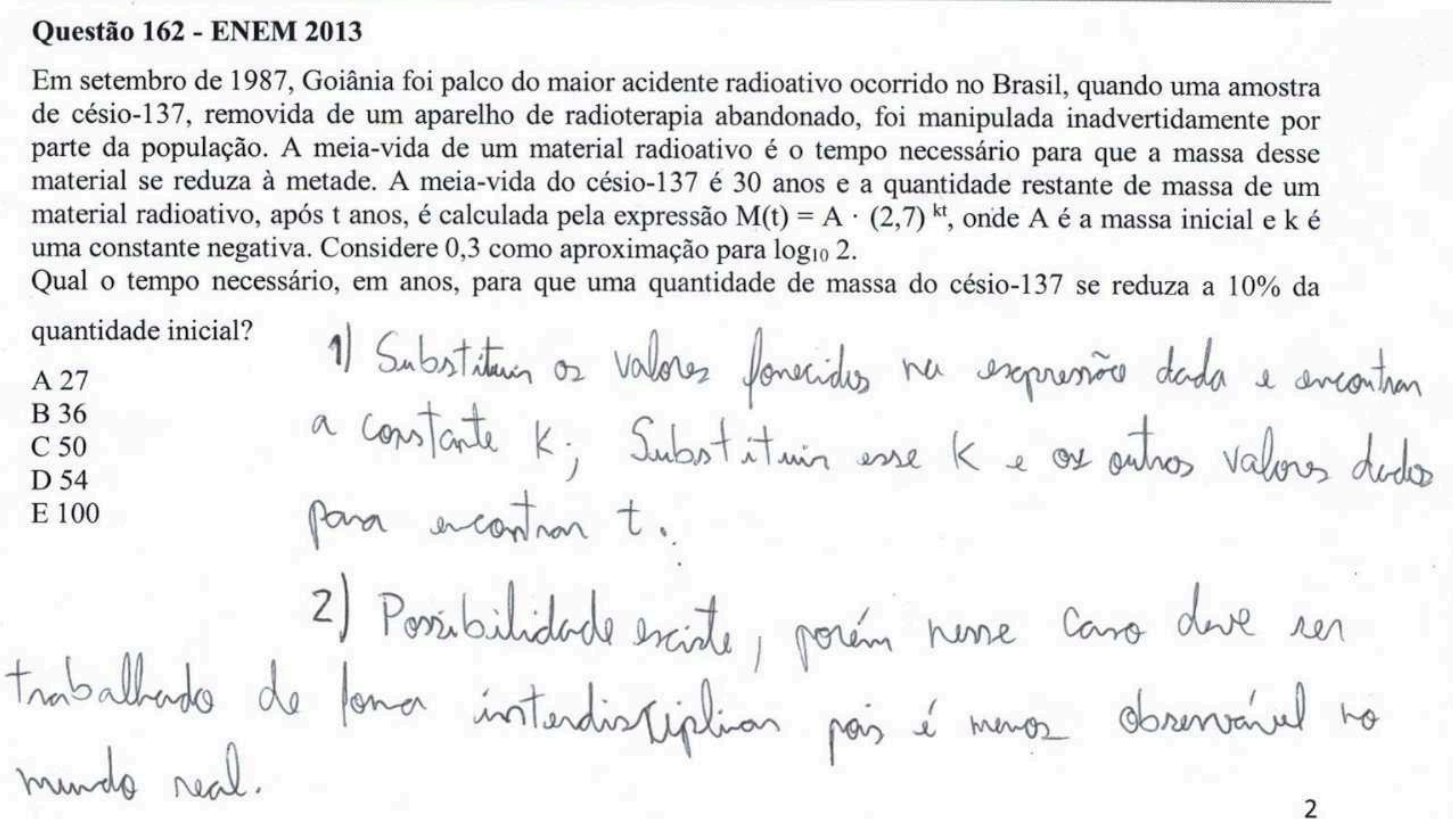

Figura 4 - Atividade 3. Questão 162-ENEM 2013. Grupo 2

Fonte: Material de pesquisa

A questão 162-ENEM 2013 (Figura 4) envolve um problema social real, que foi o acidente com o elemento químico Césio-137 ocorrido em Goiânia. Contudo, apesar de comentar que existe a possibilidade de trabalhar com as abordagens, de forma interdisciplinar, 
o grupo 2 afirma ser menos observável no mundo real. Trata-se de uma questão importante, que envolve a Ciência, a Tecnologia, um problema social e a Matemática.

\section{QUESTÃO 165 - ENEM 2014}

Durante a Segunda Guerra Mundial, para decifrarem as mensagens secretas, foi utilizada a técnica de decomposição em fatores primos. Um número $\mathrm{N}$ é dado pela expressão $2^{\mathrm{x}} \cdot 5^{\mathrm{y}}$. $7^{\mathrm{z}}$, na qual $\mathrm{x}$, y e z são números inteiros não negativos. Sabe-se que $\mathrm{N}$ é múltiplo de 10 e não é múltiplo de 7 . O número de divisores de $\mathrm{N}$, diferentes de $\mathrm{N}$, é
A) $x \cdot y \cdot z$
B) $(x+1) \cdot(y+1)$
C) $\mathrm{x} \cdot \mathrm{y} \cdot \mathrm{z}-1$
D) $(x+1) \cdot(y+1) \cdot z$
E) $(x+1) \cdot(y+1) \cdot(z+1)-1$

$$
\begin{aligned}
& \text { 1) Se aluno conseguisse resolver, } \\
& \text { revia cor técnies algíbrias. } \\
& \text { 2) Muita fouco, esse escercício } \\
& \text { é mais aplicocens de comeitor e } \\
& \text { calcubo do que aglinis ao } \\
& \text { mundo è nociedede. }
\end{aligned}
$$

Figura 5 - Atividade 3. Questão 165-ENEM 2014. Grupo 2

Fonte: Material de pesquisa

A questão 165- ENEM 2014 (Figura 5) também envolve a Ciência, a Tecnologia, um problema social real e a Matemática, e por esse motivo, possui em seu contexto a abordagem CTS e a EMC. No entanto, o grupo 2 acredita não ter uma relação direta com o mundo real e a Sociedade, sendo apenas, uma questão que envolve aplicação de conceitos e cálculos.

\section{Questão 153 - ENEM 2016}

O Brasil é o quarto produtor mundial de alimentos e é também um dos campeões mundiais de desperdício. São produzidas por ano, aproximadamente, 150 milhões de toneladas de alimentos e, desse total, $\frac{2}{3}$ são produtos de plantio. Em relação ao que se planta, $64 \%$ são perdidos ao longo da cadeia produtiva ( $20 \%$ perdidos na colheita, $8 \%$ no transporte e armazenamento, $15 \%$ na indústria de processamento, $1 \%$ no varejo e o restante no processamento culinário e hábitos alimentares). $\mathrm{O}$ desperdício durante o processamento culinário e hábitos alimentares, em milhão de tonelada, é igual a:
A) 20
B) 30
1) Interpreten i organingen
or dados; Caluular no rentide
C) 56
D) 64 inverse que as informentos foram dudas vo arenciendo.
E) 96

$$
\text { 2) Podan ser tratados en reala de aula esses dados }
$$$$
\text { reais sobre desperdício de alimentios, de fona rocierl crítiea. }
$$

Figura 6 - Atividade 3. Questão 153-ENEM 2016. Grupo 2

Fonte: Material de pesquisa 
Com relação a questão 153-ENEM 2016 (Figura 6), que contempla o desperdício de alimentos, os professores do grupo 2 acreditam que pode ser tratada de forma crítica.

Podemos compreender por meio da análise destas atividades, que os professores ainda não percebem quais são os contextos que envolvem um problema social e que por isso, podem ser tratados de forma crítica. Sendo esses os elementos que envolvem as abordagens CTS e EMC. Os professores acreditam que envolver o cotidiano é o suficiente para que as questões sejam trabalhadas em sala de aula. No entanto, tais questões não são o bastante para a formação do cidadão.

Um contexto que envolve um problema social está relacionado com as consequências que a Ciência e a Tecnologia podem ocasionar na Sociedade, associados aos interesses políticos e econômicos, bem como, às questões éticas e aos valores humanos envolvidos neste contexto.

Alguns exemplos de temas sociais apontados por Santos e Mortimer (2002) são a exploração mineral por empresas multinacionais, a privatização da Petrobrás, a ocupação urbana desordenada, o saneamento básico, o destino do lixo, o desmatamento, o controle dos produtos químicos e os riscos para a saúde, o desenvolvimento da agroindústria, a produção de alimentos e os alimentos transgênicos. São temas que por envolver a Ciência, a Tecnologia e por interferir na existência das pessoas na Sociedade, transformam-se em problemas sociais.

Tomando como base os ensinamentos de Paulo Freire (1996), os problemas sociais poderiam a princípio, buscar uma abordagem a partir de problemas locais, passando depois para uma dimensão global (SANTOS; MORTIMER; 2002).

$\mathrm{Na}$ análise da questão 162-ENEM 2013 (Figura 4), que tem como tema central o acidente com o césio-137 em Goiânia, na qual o grupo 2 afirma ser menos observável no mundo real, podemos perceber que os professores compreendem que este fato é pontual, por isso, algo distante da realidade. No entanto, esse acidente aconteceu por que as pessoas não conheciam as consequências do mau uso da Ciência e da Tecnologia. O comentário demonstra que os professores compreendem, em algumas situações, a Ciência como algo distante, que não interfere no cotidiano das pessoas.

Dessa forma, o ensino de Matemática proposto deveria estimular o aluno a compreender tais questões e a participar por meio da expressão de suas opiniões, de forma democrática, considerando que o conhecimento matemático é imprescindível na construção da cidadania, e que a Sociedade, cada vez mais, faz uso de conhecimentos científicos e recursos tecnológicos, dos quais os cidadãos devem se apropriar.

A abordagem CTS e a Educação Matemática Crítica são um caminho para este ensino, pois possibilitam a aproximação do conhecimento científico e tecnológico com os problemas sociais, promovendo a alfabetização científica e Matemática. 


\section{Atividade 4}

A atividade 4 (Quadro 8) tinha como objetivo elaborar uma questão do tipo "questão do ENEM", isto é, uma questão que contempla conteúdos matemáticos do Ensino Médio e principalmente, contextualizada. Por meio desta questão buscamos analisar se os professores compreenderam as abordagens CTS e EMC e se consideraram possível a inserção destas abordagens em sua prática.

Quadro 8 - Atividade 4

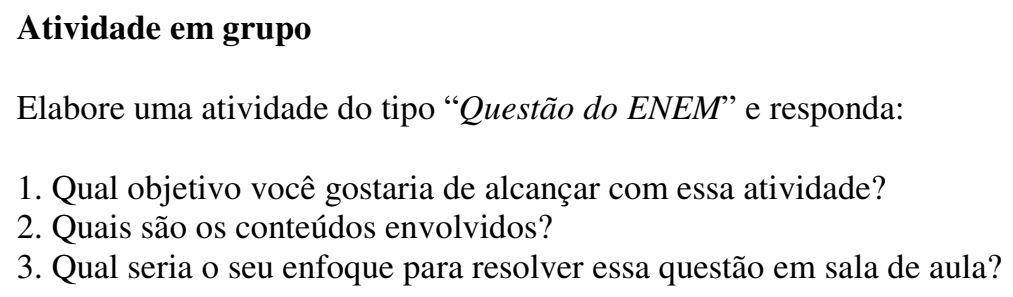

Fonte: os autores

Com o objetivo de verificar se os professores perceberam que contextualizar suas atividades com aspectos sociais e políticos da Matemática, contribui com um ensino que promove a aplicação do conhecimento matemático associado a reflexão da realidade, a atividade 4 (Quadro 8) deveria abordar aspectos históricos e/ou éticos, políticos, socioeconômicos no contexto da questão, como orientado pela abordagem CTS, conforme Santos (2010), e/ou um contexto onde houvesse a problematização da realidade, como aponta a EMC (SKOVSMOSE, 2011). Esta atividade também foi realizada em grupo e deveria ser entregue por escrito, como também, apresentada para todos os participantes.

O grupo 1 elaborou uma questão que envolvia como conteúdo matemático a geometria, e o contexto contemplava a criação de embalagens, porém, preocupando-se com a redução de desperdícios e o meio ambiente. O grupo comentou sobre a dificuldade que os estudantes possuem em resolver problemas, muitas vezes associados a dificuldade de interpretação. Além da necessidade de reflexão sobre os contextos e os resultados obtidos, como cita Skovsmose (2011) sobre o conhecimento reflexivo.

O grupo 2 desenvolveu uma questão, que no início, não envolveu um problema social diretamente. Os conteúdos envolvidos seriam sistema de equação, álgebra e as operações fundamentais, com foco na resolução de problemas e o contexto seria próximo do cotidiano do estudante, neste caso, escolheram alimentos de uma lanchonete. No entanto, no momento da apresentação, o grupo sugeriu que a atividade proporciona discussões em sala de aula, em relação a alimentação saudável, também em relação ao desperdício e a economia doméstica.

O grupo 3 criou uma questão que, além de envolver diversos conteúdos da Matemática, como grandezas, medidas, operações básicas, também contemplou um problema ambiental real, que foi o desastre ocorrido na cidade de Mariana-MG. Primeiramente, o 
grupo apresentaria aos estudantes a notícia sobre o acidente, esclarecendo que foram jogados 62 milhões de $\mathrm{m}^{3}$ de rejeitos de mineração, promovendo uma discussão sobre esse assunto. Depois, apresentaria uma questão para ser resolvida matematicamente. A questão teria o seguinte enunciado: "Considerando que cada habitante consome cerca de $5 \mathrm{~m} 3$ de água por mês e considerando que os $100 \%$ dos rejeitos de minério do desastre de Mariana - MG (62 milhões de $\mathrm{m}^{3}$ de mineração) fossem água, quais cidades brasileiras poderiam ser abastecidas com essa água, durante um mês?"

Esse problema real teria como resultado o número de 12.400.000 habitantes que poderiam consumir a água desperdiçada no desastre, em um mês. Após a obtenção do resultado, o grupo comentou que poderiam trabalhar com a confecção de gráficos de setor da população brasileira, para comparar com o consumo de água por estado ou região do Brasil. Se relacionarmos os resultados com o consumo de água dos estados brasileiros, seria possível concluir que a água desperdiçada poderia abastecer quase todos os estados brasileiros, exceto os estados de São Paulo, Rio de Janeiro, Minas Gerais e Bahia.

O grupo 4 elaborou uma questão que envolvia cálculos trigonométricos e o contexto seria o "pouso de um avião". No entanto, apesar de ter comentado que a questão envolvia o cotidiano dos estudantes, não houve relação do contexto que envolvesse a Ciência, a Tecnologia com um problema social.

Desta forma, apenas os grupos 1, 2 e 3 elaboraram questões que possuíam em seu contexto, uma relação com um problema social, uma Tecnologia relacionada a um tema social, um conteúdo científico definido em função de um tema social (SANTOS \& MORTIMER, 2002). No entanto, mesmo depois de apresentarmos e discutirmos as abordagens, um grupo não incluiu um problema social no contexto da questão, levando-nos a constatar que para esse grupo, não ficou claro o que consiste tais abordagens.

\section{Atividade Final}

A partir da atividade final (Figura 11), buscamos averiguar se o Curso de Extensão colaborou para a compreensão das abordagens CTS e EMC, como também, se os professores entenderam que a inserção das abordagens no ensino de Matemática contribui para um ensino de Matemática contextualizado, a partir da relação entre a Ciência, a Tecnologia e problemas sociais.

Quadro 9 - Atividade Individual

\section{Atividade Individual}

Responda:

Após a participação no curso de extensão, qual é o seu entendimento e quais são as contribuições da Educação Matemática Crítica e da abordagem CTS na e para a sua prática?

Fonte: os autores 
Na resolução da Atividade Individual (Quadro 9), dois professores mencionaram a similaridade das abordagens CTS e EMC, quatro descreveram que consideraram importante participar do Curso de Extensão, ressaltando que contribui com a prática em sala de aula, dois consideraram importantes as abordagens no ensino e quatro professores destacaram a contextualização como necessária no ensino de Matemática. Desta forma, os doze participantes demonstraram em suas respostas que houve um entendimento sobre as abordagens CTS e EMC. Nesse sentido, apresentaremos alguns recortes que demonstram as respostas dos professores.

$\mathrm{O}$ relato do professor P4 enfatizou a proximidade da EMC e da Abordagem CTS, como podemos perceber na transcrição.

Acredito que a EMC e a abordagem CTS, ambas possuem tópicos muito similares, sendo que a EMC pode ser considerada o uso da abordagem CTS na Matemática. O uso da EMC ajuda a "quebrar" a velha forma de ensino, e faz com que o aluno deixe de ser um calculista e passe a ser um cidadão crítico. Com o curso pude conhecer a EMC e a abordagem CTS, o que me fez perceber que eu já as usava sem conhecelas, porém, que eu posso aprimorar minha forma de ensino (P4).

O professor P4 demonstrou perceber a aproximação das abordagens CTS e EMC e ressaltou o auxílio da EMC para romper com "a velha forma de ensino", fazendo menção ao ensino tradicional, contribuindo para que o "aluno deixe de ser um calculista e passe a ser o cidadão crítico", demonstrando reconhecer que as abordagens CTS e EMC podem contribuir com um ensino de Matemática que auxilia na interpretação da realidade.

Contextualizar é inserir o aluno ao meio da Matemática utilizando linguagens, informações e fatos mais factíveis com a realidade. Despertar o prazer e a gana de saber do aluno com assuntos polêmicos ou universais. A Matemática Crítica nos permite trabalhar com fatos reais e discutir e aprofundar o conhecimento dos alunos naquele assunto em si. A abordagem CTS faz com que o professor possa inserir o aluno em ambientes multidisciplinares e provoca pensamentos sociais e científicos sobre a realidade (P10).

O participante P10 destacou pontos importantes estudados no Curso de Extensão, como a interpretação da realidade através da EMC, a importância de incentivar os estudantes a discutir assuntos "polêmicos ou universais", ou seja, problemáticas sociais, além de reconhecer que a abordagem CTS envolve outras disciplinas e busca a reflexão sobre pensamentos sociais e científicos.

O professor P2 apontou termos importantes referentes às abordagens CTS e EMC, como Alfabetização Científica, contextualização e questões da vida moderna

Acredito que a abordagem CTS contribui para alavancar a contextualização, para subsidiar o aluno com aspectos e conceitos científicos (alfabetização científica), para refletir sobre as "questões da vida moderna". A Matemática Crítica já contribui para a própria cientificidade do processo: a compreensão do resultado, os "porquês", a aplicabilidade, a reflexão. Ambas (EMC e CTS) contribuirão muito na minha prática, pois abriram portas para novas práticas e explorar mais assuntos, para convidar os alunos a perceberem a Matemática além da Matemática (P2). 
O professor P2 demonstrou reconhecer que a abordagem CTS contribui para a contextualização de aspectos e conceitos científicos. E ainda, evidenciou que compreendeu o papel social da Educação Matemática quando mencionou que as abordagens CTS e EMC contribuirão muito para a sua prática, para "convidar" os estudantes a "perceberem a Matemática além da Matemática” (P2).

\section{Considerações}

Para responder aos questionamentos de como os professores compreendem as abordagens CTS e EMC e de que maneira eles incorporam a temática em sua prática, analisamos as questões 3 e 4 do Questionário, atividade 1 (Quadro 3) e verificamos que os professores compreendiam que existe uma relação entre a Ciência, a Tecnologia e a Sociedade, porém, não conheciam a abordagem CTS e não incorporavam a temática em sua prática. E ainda, não conheciam a EMC e a sua importância no ensino.

Acreditamos que, um dos fatores que resultam no desconhecimento dos professores em relação a tais abordagens, tem origem na formação inicial que, na maioria dos cursos, não contemplam essas abordagens. A inclusão dos estudos sociais da Ciência e da Tecnologia nos cursos de Licenciatura poderia proporcionar ao professor uma reflexão sobre o papel social da Ciência e da Tecnologia, contribuindo para a inserção desses assuntos em suas aulas.

Ao final do Curso de Extensão, pudemos constatar que os doze professores descreveram algo que demonstrasse compreensão sobre a abordagem CTS e a EMC e a relevância desses assuntos para o ensino de Matemática.

O Curso de Extensão proposto neste relato de pesquisa abordou conteúdos matemáticos, por meio das questões do ENEM, possibilitando discussões sobre questões ligadas a resolução de problemas, mas principalmente, chamou a atenção dos professores para a dimensão social e cultural do ensino da Matemática. Refletimos sobre termos importantes como a contextualização, a Alfabetização Científica, a Alfabetização Matemática, a dimensão social dos conhecimentos científicos e tecnológicos. As intervenções propostas no Curso de Extensão tornaram possíveis a socialização dos conhecimentos e das práticas, proporcionando a construção coletiva do conhecimento.

Neste contexto, salientamos a importância dos cursos de formação continuada, pois oportunizam ao professor novas possibilidades didático-pedagógicas e ainda, contribuem com discussões importantes sobre as diversas situações de ensino-aprendizagem e dificuldades vivenciadas na Educação Básica.

Compreendemos que a abordagem CTS e a EMC são complementares, quando nos referimos ao ensino de Matemática, que contempla os conhecimentos científico-tecnológicos, com a finalidade de formar o cidadão que compreende e questiona a influência das decisões 
sobre a Ciência e a Tecnologia na Sociedade. Para tanto, a formação do professor que ensina

Matemática deve ser direcionada para uma concepção de Ciência e Tecnologia que considera o contexto social e reflete sobre o papel da Matemática na Sociedade atual.

Desta forma, acreditamos que uma possível estratégia seria utilizar as questões do ENEM como instrumento de ensino-aprendizagem para a introdução das abordagens CTS e EMC no ensino de Matemática na Educação Básica.

\section{Referências}

AULER, D. Enfoque ciência-tecnologia-sociedade: pressupostos para o contexto brasileiro. Ciência \& Ensino, v. 1, p. 01-20, 2007.

AULER, D. Novos caminhos para a educação CTS: ampliando a participação. In: SANTOS, W. L. P.; AULER D. (Org.), CTS e educação científica: desafios, tendências e resultados de pesquisas. Brasília: Universidade de Brasília, 2011. p. 73-97.

BARDIN, L. Análise de conteúdo. Tradução Luís Antero Reto e Augusto Pinheiro. São Paulo: Edições 70, 2011.

BAZZO, W. A.; PALACIOS, E.M.G., GALBARTE, J. C. G.; LINSINGEN, I. V., CEREZO, J. A. L.; LUJÁN, J. L.; VALDÉS, C. Introdução aos estudos CTS Ciência, Tecnologia e Sociedade. Cadernos de Ibero-América, Editora OEI, 2003. Disponível em:

https://www.oei.es/historico/salactsi/introducaoestudoscts.php. Último acesso: 08 nov.2018

BAZZO, W. A.; CURY, H. N. Formação crítica em matemática: uma questão curricular? Bolema, v.1 4, n. 16, p. 29-47, 2001.

BIZZO, N. M.V. Pensamento científico: a natureza da ciência no ensino fundamental. São Paulo: Editora Melhoramentos, 2013.

BORBA, M. C.; SKOVSMOSE, O. A ideologia da certeza em educação Matemática. In: SKOVSMOSE, O. Educação Matemática Crítica - A Questão da Democracia. Campinas: Papirus, 2011.

BRASIL. ENEM - Exame Nacional do Ensino Médio: documento básico. Inep. Brasília, 2002.

CHALMERS, A. F. O que é ciência afinal? Tradução: Raul Filker. São Paulo: Brasiliense, 1993.

CHAUÍ, M. Um convite à filosofia. São Paulo: Ática, 2000.

DAL-FARRA, R. A. Matemática e educação matemática: aproximações epistemológicas, cultura e discursos contemporâneos. Zetetiké: Revista de Educação Matemática; v. 18, n. temático, p. 504-544, 2010.

FIORENTINI, D. Alguns modos de ver e conceber o ensino de Matemática no Brasil. Zetetiké: Revista de Educação Matemática, v. 4, n. 01, p. 1-36, 1995. 
FIORENTI, D. A formação Matemática e didático pedagógica nas disciplinas da licenciatura em Matemática. Revista de Educação, v. 10, n. 18, p. 107-115, 2005.

FOUREZ, G. A construção das Ciências: introdução à Filosofia e à ética das Ciências. Tradução de Luiz Paulo Rouanet. São Paulo: Editora da Universidade Estadual Paulista, 1995.

FREIRE, P. Pedagogia da autonomia: saberes necessários à prática educativa. São Paulo: Paz e Terra, 1996.

GUAZELLI, I. R. B.; MACIEL, M. D.; SOLIGO, M. G.; NASCIMENTO, D. S.; MACEDO, H. C. Alfabetização científica crítica e cultura em uma perspectiva CTSA. In: AMARAL C. L. C.; CURI E. (Org.), Pesquisas e Práticas de Ensino em Química \& Biologia. São Paulo: Terracota, 2009. p. 12-41.

LIMA, R. S.; PIMENTEL, L. C. F.; AFONSO, J. C. O despertar da radioatividade ao alvorecer do século XX. Química Nova na Escola, v. 33, p. 93-98, 2011.

MORIN, E. Ciência com consciência. Tradução de Maria D. Alexandre e Maria Alice Sampaio Dória. Rio de Janeiro: Bertrand Brasil, 2005.

SANTOS, W. L. P.; MORTIMER, E. F. Uma análise de pressupostos teóricos da abordagem CTS (Ciência-Tecnologia-Sociedade) no contexto da Educação Brasileira. Ensaio - Pesquisa em Educação em Ciênicas, v. 2, n. 2, p. 133-162, 2002.

SANTOS, B. S. Um discurso sobre as ciências. São Paulo: Cortez, 2010.

SANTOS, M. E. V. M. A dimensão CTS do ensino das ciências: fundamentos, contextos e desafios. In: MACIEL, M. de L.; AMARAL, C. L. C.; GUAZELLI, I. R. B. (Org.) Ciência, tecnologia e sociedade: pesquisa e ensino. São Paulo: Terracota, 2010, p. 71-91.

SASSERON, L. H.; CARVALHO, A. M. P. Alfabetização científica: uma revisão bibliográfica. Investigações em Ensino de Ciências; v. 16, n. 1, p. 59-77, 2011.

SBRANA, M. F. C. A contextualização da Matemática a partir da abordagem cts na perspectiva da educação Matemática crítica. Dissertação de mestrado em Ensino e História das Ciências e Matemática - Universidade Federal do ABC, Santo André, 2017.

SEPINI, R.P.; MACIEL, M. D. Como o ensino de questões relacionadas com natureza da ciência e tecnologia pode contribuir para a formação de futuros professores. Indagatio Didactica, v. 8, n. 1, p. 739-751, 2016.

SILVA, M. P.; ALBRECHT, E. A formação de professores sob o enfoque da ciência, tecnologia e sociedade. In: MACIEL, M. de L.; AMARAL, C. L. C.; GUAZELLI, I. R. B. (Org.) Ciência, tecnologia e sociedade: pesquisa e ensino. São Paulo: Terracota, 2010. p. 157-164.

SKOVSMOSE, O. Educação Matemática crítica: a questão da democracia. Campinas: Papirus, 2011.

SKOVSMOSE, O. Ole Skovsmose e sua educação Matemática crítica. Entrevista concedida CEOLIM, A. J.; HERMANN, W. Revista Paranaense de Educação Matemática, v.1, 2012. Disponível em: http://www.fecilcam.br/revista/index.php/rpem/article/view/860. Último acesso em: 08 nov.2018. 


\section{SOBRE OS AUTORES}

MARIA DE FÁTIMA COSTA SBRANA. Mestre em Ensino e História das Ciências e Matemática pela Universidade Federal do ABC, especialista em Educação Matemática pela Faculdade Oswaldo Cruz, bacharel em Matemática pelo Centro Universitário Fundação Santo André e licenciada em Matemática e Física pela Universidade Metodista de São Paulo, colaboradora do grupo de pesquisa Gecimas - Grupo de Estudos e Pesquisa em Educação em Ciências, Matemática e Sexualidade na linha de pesquisa Ensino e Aprendizagem em Ciências e Matemática na UFABC. Atualmente é professora de Matemática na rede pública municipal e autora de livros didáticos.

EVONIR ALBRECHT. Formado em Magistério, para atuar com os anos iniciais da Educação Básica pelo Colégio Cenecista Marechal Arthur da Costa e Silva de Guarujá do Sul, SC; Atuou nos anos iniciais por quatro anos; Licenciado em Matemática com habilitação em Física pela Universidade do Oeste de Santa Catarina; Especialista em Psicopedagogia e Ensino de Física; Mestre e Doutor em Ensino de Ciências e Matemática pela Universidade Cruzeiro do Sul; Professor das redes públicas municipais e estaduais de Educação Básica nos estados de Santa Catarina e São Paulo; Professor nas Universidades Nove de Julho e Cruzeiro do Sul na cidade de São Paulo; Atualmente é Professor Adjunto na Universidade Federal do ABC na graduação e pós-graduação. Atua junto ao Programa de Pós-Graduação da UFABC, nas linhas de pesquisa: ensino, aprendizagem, currículo, CTS, estágio supervisionado, ensino de astronomia.

MARCIA AGUIAR. Possui graduação em Licenciatura em Matemática pela Universidade de São Paulo (1994), mestrado em Educação pela Universidade de São Paulo (1999), mestrado em Matemática pela Universidade de São Paulo (2005) e doutorado em Educação pela Universidade de São Paulo (2014). Lecionou em escolas públicas e particulares no Ensino Básico e, em Ensino Superior. Autora de Matemática do Programa Acelera Brasil do Instituto Ayrton Senna. Atualmente é professora adjunto da Universidade Federal do ABC. Sua área de pesquisa está relacionada ao Ensino de Matemática, Ensino de Álgebra e Formação de Professores.

Recebido: 28 de março de 2018.

Revisado: 04 de setembro de 2018.

Aceito: 11 de outubro de 2018. 